\title{
CD155 and CD112 as possible therapeutic targets of FLT3 inhibitors for acute myeloid leukemia
}

\author{
YUTA KAITO $^{1}$, MITSUHITO HIRANO ${ }^{2}$, MUNEYOSHI FUTAMI ${ }^{2}$, MASANORI NOJIMA $^{3}$, \\ HIDETO TAMURA $^{4}$, ARINOBU TOJO ${ }^{1,2}$ and YOICHI IMAI ${ }^{1}$ \\ ${ }^{1}$ Department of Hematology/Oncology, Research Hospital; ${ }^{2}$ Department of Molecular Therapy, \\ Advanced Clinical Research Center; ${ }^{3}$ Department of Translational Research, The Institute of Medical Science, \\ The University of Tokyo, Tokyo 108-8639; ${ }^{4}$ Department of Hematology, Saitama Medical Center, \\ Dokkyo Medical University, Saitama 343-8555, Japan
}

Received September 21, 2021; Accepted November 17, 2021

DOI: $10.3892 / \mathrm{ol} .2021 .13169$

\begin{abstract}
Acute myeloid leukemia (AML) relapse is considered to be related to escape from antitumor immunity. Changes in the expression of immune checkpoints, including B7 homolog (H)1 and B7-H2, have been reported to contribute to AML progression. Binding of $\mathrm{T}$ cell immunoglobulin and immunoreceptor tyrosine-based inhibitory motif domain (TIGIT) among other immune checkpoints on natural killer (NK) and T cells to CD155/CD112 in tumors is supposed to be inhibitory; however, the mechanism by which changes in CD155 and CD112 expression affect tumor immunity remains unclear. When the increased expression of CD155 and CD112 activates Raf-MEK-ERK pathway and Raf-MEK-ERK pathway is one of the targets of FMS-like tyrosine kinase 3 (FLT3) inhibition. The present study investigated the alterations in CD155 and CD112 expression under FLT3 inhibition (quizartinib and gilteritinib) and studied its effect on $\mathrm{NK}$ and $\mathrm{T}$ cell cytotoxicity. CD155 and CD112 expression was analyzed using flow cytometry and reverse transcription-quantitative PCR in AML cell lines with or without FLT3 mutation using FLT3 inhibitors. CD155 and CD112 expression was specifically downregulated by FLT3 inhibition in FLT3-mutated cell lines. Direct cytotoxicity and antibody-dependent cellular cytotoxicity against these cells by NK cells were enhanced. However, the cytotoxicity of $\gamma \delta \mathrm{T}$ cells with low TIGIT expression compared with NK cells was not enhanced in direct cytotoxicity assay using luciferase luminescence. The analysis of clinical trials from The Cancer Genome Atlas (TCGA) revealed that high CD155 and CD112 expression is
\end{abstract}

Correspondence to: Dr Yoichi Imai, Department of Hematology/Oncology, Research Hospital, The Institute of Medical Science, The University of Tokyo, 4-6-1, Shirokanedai, Minato-ku, Tokyo 108-8639, Japan

E-mail: imaiyo-tky@umin.ac.jp

Key words: acute myeloid leukemia, immune checkpoint, CD155, CD112, FMS-like tyrosine kinase 3 inhibitor, natural killer cell associated with poor overall survival. The enhanced cytotoxicity of NK cells against CD155- and CD112-downregulated cells following FLT3 inhibition indicated CD155 and CD112 as possible targets of immunotherapy for AML using FLT3 inhibitors.

\section{Introduction}

The anti-leukemia role of natural killer (NK) cells has been indicated by study of the prevention of relapse by alloreactive NK cells in hematopoietic stem cell transplantation (SCT) (1). A recent study demonstrated the involvement of impaired NK cell function in the immune evasion of leukemic cells (2). NK cells are one of the key players in the innate immune response characterized by tumor cell destruction (3). The balance between activation and inhibition mediated by different receptors controls NK cell activation (4). This balance is supposed to be regulated by the Nectins and Nectin-like molecules (Necls) family, including the activating receptor DNAX accessory molecule-1 (DNAM-1; also known as CD226) and the inhibitory axis comprising $\mathrm{T}$ cell immunoglobulin and immunoreceptor tyrosine-based inhibitory motif domain (TIGIT) (5). DNAM-1 and TIGIT share the same ligands, CD155 (Necl-5) and/or CD112 (Nectin-2), and these molecules are immune checkpoints, such as programmed cell death protein-1 (PD-1) and programmed death-ligand 1 (PD-L1) $(3,6,7)$.

FMS-like tyrosine kinase 3 (FLT3), a receptor tyrosine kinase, serves a major role in the regulation of hematopoiesis (8). Mutations in FLT3, including the internal tandem duplication (ITD), which is the most common type of FLT3 mutation, occurs in $\sim 30 \%$ of all acute myeloid leukemia (AML) cases (9,10). FLT3-ITD leads to a high leukemic burden and confers a poor prognosis in patients with AML (10). First-generation FLT3 inhibitors developed for clinical use in patients with mutated FLT3 are broad-spectrum, multikinase inhibitors and lack specificity for the mutated FLT3-ITD, which may explain their transient anti-leukemic activity, particularly when used as monotherapy in patients with relapsed disease (11). Next-generation FLT3 inhibitors, including quizartinib and gilteritinib, have greater specificity for FLT3 
and higher potency compared with the first-generation FLT3 inhibitors (12). These FLT3 inhibitors have shown promising anti-leukemia effects in single agent in clinical trials, and their clinical use has been approved by the US Food and Drug Administration $(13,14)$.

Regarding the relevance of FLT3 mutations and TIGIT, the frequencies of $\mathrm{CD}^{+} \mathrm{T}$ cells expressing TIGIT and PD-1 without DNAM-1 were higher in patients with FLT3-ITD mutations than in those without these mutations (15). However, to the best of our knowledge, the relevance of CD155 and CD112, cognate ligands of TIGIT, in AML prognosis and their effect on NK cell function remain unclear.

The present study analyzed the mRNA expression of CD155 and CD112 via reverse transcription-quantitative (RT-q)PCR in AML cells with FLT3 mutations treated with FLT3 inhibitors. Surface expression of CD155 and CD 112 in AML cells with or without FLT3 mutations treated with FLT3 inhibitors was also analyzed by flow cytometry. Furthermore, the present study investigated whether the anti-leukemic effect of NK and $\gamma \delta$ T cells was affected by treatment of AML cells with FLT3 inhibitors.

\section{Materials and methods}

Cell lines and culture conditions. Human AML cell lines (MOLM-13, MV-4-11, THP-1, NB-4 and KG-1) and a chronic myeloid leukemia (CML) cell line (K562) were cultured in RPMI-1640 medium (FUJIFILM Wako Pure Chemical Corporation) $10 \%$ fetal bovine serum (FBS; Sigma-Aldrich; Merck $\mathrm{KGaA}$ ) and $1 \%$ penicillin-streptomycin at $37^{\circ} \mathrm{C}$ in an atmosphere with $5 \% \mathrm{CO}_{2}$. KHYG-1 cells were cultured in RPMI-1640 medium supplemented with 10\% FBS and $1 \%$ penicillin/streptomycin in the presence of $2-20 \mathrm{ng} / \mathrm{ml}$ recombinant human IL-2 (rhIL-2, PeproTech) at $37^{\circ} \mathrm{C}$ with $5 \% \mathrm{CO}_{2}$. MV-4-11, THP-1, KG-1, K562 and NB-4 cells were obtained from American Type Culture Collection. KHYG-1 cells were obtained from Japanese Collection of Research Bioresources Cell Bank, whereas MOLM-13 cells were obtained from Leibniz Institute DSMZ (German Collection of Microorganisms and Cell Cultures).

Primary cells. NK cells were purified from peripheral blood mononuclear cells (PBMCs) obtained from healthy donors (age, 20-65 years, three males and one female) from October 2019 to September 2021 at Research Hospital, The Institute of Medical Science, The University of Tokyo, Tokyo, Japan, using a human NK Cell Isolation Kit (Miltenyi Biotec GmbH). Cell counting was performed using a hemocytometer (Erma Inc.). The $\gamma \delta$ $\mathrm{T}$ cell isolation protocol as described by Cui et al (16) was followed. Briefly, $\gamma \delta$ T cells were isolated from PBMCs under stimulation with zoledronic acid (Selleck Chemicals) at $1 \mu \mathrm{M}$, in combination with $50 \mathrm{IU} / \mathrm{ml}$ rhIL-2 at $37^{\circ} \mathrm{C}$ with $5 \% \mathrm{CO}_{2}$ for 7 days. The culture media were changed every 3 days. After 1 week of culture, the cells were harvested and $\mathrm{CD}^{+} \mathrm{Vd} 2 \mathrm{~T}$ cell receptor $(\mathrm{TCR})^{+}$cells were determined by flow cytometry.

Lentiviral production and transduction. Lenti-X293T cells (Clontech; Takara Bio USA) were cultured in DMEM (FUJIFILM Wako Pure Chemical Corporation) with $10 \%$ FBS and $1 \%$ penicillin-streptomycin, at $37^{\circ} \mathrm{C}$ with $5 \% \mathrm{CO}_{2}$.
Lentiviral plasmid (CSII-EF-MCS) was purchased from National BioResource Project and 3rd generation system was used. Lentiviral plasmid (CSII-EF-fLuc-2A-EGFP) was produced as described previously (17). Lentiviral vector (CSII-EF-fLuc-2A-EGFP) particles ( $5 \mu \mathrm{g}$ ) were produced by cotransfection of Lenti-X293T cells with a transfer plasmid, and packaging plasmids pMDLg/p.RRE $(3 \mu \mathrm{g})$, pRSV-rev $(1 \mu \mathrm{g})$ and pMD.G $(1 \mu \mathrm{g})$ at $37^{\circ} \mathrm{C}$ with $5 \% \mathrm{CO}_{2}$ for 2 days. The lentiviral particles were obtained by centrifugation at $400 \mathrm{x} \mathrm{g}$ and $4{ }^{\circ} \mathrm{C}$ for $5 \mathrm{~min}$ and collection of supernatant. Then the lentiviral vector particles were titrated in HeLa cells as described previously (18). A total of $1 \times 10^{6}$ Target cells (MOLM-13, MV-4-11 and THP-1) were transduced with the CSII-EF-fLuc-2A-EGFP lentiviral vector at a multiplicity of infection of 5. Two days after transduction, target cells $\left(\mathrm{EGFP}^{+}\right)$were harvested by fluorescence-activated cell sorting using a cell sorter SH800s (Sony Corporation) and expanded for an additional 5 days.

Reagents. Quizartinib (AC220) was obtained from Selleck Chemicals and Daiichi Sankyo Co., Ltd. Gilteritinib (ASP2215) was obtained from Selleck Chemicals. Trametinib (cat. no. GSK-1120212) was obtained from MedChemExpress. Each chemical was dissolved in DMSO and added to the culture medium at 1-100 $\mathrm{nM}$ for in vitro experiments. Daratumumab for in vitro experiments was purchased from Janssen Pharmaceutical K.K.

Flow cytometry (AML and CML). AML cell lines (MOLM-13, MV-4-11, THP-1, NB-4 and KG-1) and a CML cell line (K562) were exposed to FLT3 inhibitors (quizartinib and gilteritinib) or MEK inhibitor (trametinib) at $37^{\circ} \mathrm{C}$ for $48 \mathrm{~h}$. The cells were subsequently harvested, and changes in CD155 and CD112 expression were analyzed. AML cell lines (MOLM-13, MV-4-11, THP-1, NB-4 and KG-1) and a CML cell line (K562) were stained with phycoerythrin (PE) anti-human CD155 (cat. no. 337508; BioLegend, Inc.), PE anti-human CD112 (cat. no. 337410; BioLegend, Inc.) and PE anti-human CD38 (cat. no. 356604; BioLegend, Inc.) antibodies. Changes in marker expression were assessed by comparing the mean fluorescence intensity of CD155 and CD112 between inhibitor-exposed and DMSO-exposed cell lines. Three independent experiments were performed. PE and FITC were detected by blue laser $(488 \mathrm{~nm})$. Flow cytometric analysis was performed using a BD FACSCelesta Flow Cytometer (BD Biosciences). Data were analyzed using FlowJo software (ver. 10.8.0, FlowJo LLC.).

Flow cytometry $(\gamma \delta$ T cells $) . \gamma \delta$ T cells were stained with FITC anti-human CD3 (cat. no. 300405; BioLegend, Inc.), allophycocyanin (APC) anti-human TCR Vd2 (cat. no. 331417; BioLegend, Inc.) and PE anti-human TIGIT (cat. no. 372704; BioLegend, Inc.) antibodies. PE and FITC were detected by blue laser $(488 \mathrm{~nm})$. APC was detected by red laser $(638 \mathrm{~nm})$. Flow cytometric analysis was performed using a BD FACSCelesta Flow Cytometer (BD Biosciences). Data were analyzed using FlowJo software (ver. 10.8.0; FlowJo LLC.).

Flow cytometry (KHYG-1 cells). KHYG-1 cells were stained with PE anti-human TIGIT antibodies (cat. no. 372704; BioLegend, Inc.). PE was detected by blue laser (488 nm). Flow 
cytometric analysis was performed using a BD FACSCelesta Flow Cytometer (BD Biosciences). Data were analyzed using FlowJo software (ver. 10.8.0, FlowJo LLC.).

Reverse transcription-quantitative PCR (RT-qPCR). All AML cell lines were exposed to FLT3 inhibitors (quizartinib and gilteritinib) at $10 \mathrm{nM}$ and DMSO at $37^{\circ} \mathrm{C}$ for $0,6,12$ or $24 \mathrm{~h}$. After treatment, total RNA was extracted from AML cells using RNeasy Mini Kit (cat. no. 74104; Qiagen GmbH). cDNA was synthesized from total RNA using the SuperScript III First-Strand Synthesis System (cat. no. 18080051; Thermo Fisher Scientific, Inc.). Using the SuperScript III First-Strand Synthesis System, RT was performed at $25^{\circ} \mathrm{C}$ for $10 \mathrm{~min}, 50^{\circ} \mathrm{C}$ for $50 \mathrm{~min}$, and $85^{\circ} \mathrm{C}$ for $5 \mathrm{~min}$. qPCR thermocycling conditions were as follows: Initial denaturation at $95^{\circ} \mathrm{C}$ for $10 \mathrm{~min}$, followed by 39 cycles of $95^{\circ} \mathrm{C}$ for $15 \mathrm{sec}$ and $60^{\circ} \mathrm{C}$ forl min. Using CFX Manager Software (ver. 2.1; Bio-Rad Laboratories, Inc.), the target gene was quantified by the $2^{-\Delta \Delta \mathrm{Cq}}$ method (19). All RT-qPCR assays were performed in triplicate. 18S ribosomal RNA was used as an internal control, confirming that its expression was consistent in tumor cell lines and was not affected by FLT3 inhibitors. CD155 and CD112 expression in AML cell lines was normalized to that of $18 \mathrm{~S}$ ribosomal RNA. The expression levels of CD155 and CD112 after each $0,6,12$, and $24 \mathrm{~h}$ exposure to DMSO or FLT3 inhibitor were divided by the expression levels of CD155 or CD112 after $0 \mathrm{~h}$ of DMSO administration and expressed as a ratio. RT-qPCR experiments were performed using TaqMan Universal Master Mix II, no UNG (Thermo Fisher Scientific, Inc.) and the CFX Connect Real-Time PCR Detection System (Bio-Rad Laboratories, Inc.). The following primers were used: TaqMan Gene Expression Assays (Thermo Fisher Scientific, Inc.) for CD155 (Hs.00197846), CD112 (Hs.01071562) and 18S (Hs.99999901). Details of the primer sequences were not provided by the company.

Antibody-dependent cellular cytotoxicity (ADCC) and NK cell direct cytotoxicity assays. Luciferase-expressing AML cell lines were exposed to FLT3 inhibitor $(10 \mathrm{nM})$, MEK inhibitor $(100 \mathrm{nM})$ or DMSO at $37^{\circ} \mathrm{C}$ for $24 \mathrm{~h}$. For the ADCC assay, AML cells were treated with 0.1 or $10 \mu \mathrm{g} / \mathrm{ml}$ daratumumab or control (IgG) and cocultured with NK cells at a ratio of $10: 1$ at $37^{\circ} \mathrm{C}$ for $4 \mathrm{~h}$. For the direct cytotoxicity assay, AML cells were coincubated with NK cells at an effector/tumor ratio of $0-30: 1$ at $37^{\circ} \mathrm{C}$ for $72 \mathrm{~h}$. Cell death was calculated from the decrease in luciferase activity, which was detected using Steady Glo (Promega Corporation). Luciferase luminescence in the samples was evaluated using a Nivo spectrophotometer (PerkinElmer, Inc.). Both assays were repeated at least thrice.

Cancer genome atlas program analysis. Data from The Cancer Genome Atlas (TCGA) program [https://www. cancer.gov/about-nci/organization/ccg/research/structural-genomics/tcga, (20)] were analyzed using cBioPortal (ver. 3.7.16) for Cancer Genomics (https://www.cbioportal. org/). The mRNA expression of TCGA data was set to a high value with a threshold Z-score of 1.8. The overall survival (OS) curve by Kaplan-Meier method was analyzed using the log-rank test by cBioPortal.

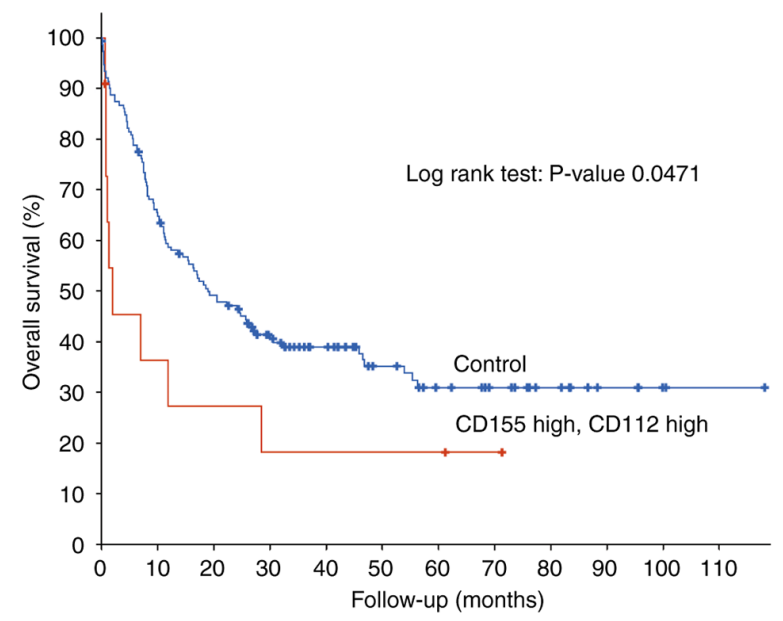

Figure 1. Higher CD155 and CD112 mRNA expression is significantly associated with poor overall survival $[n=162(C D 155 / C D 112$ high group, $n=11$; and control group, $\mathrm{n}=151) ; \mathrm{P}=0.0471]$.

Statistical analysis. All data are presented as the mean \pm SD. Differences between the two groups of samples were analyzed by a one-tailed unpaired t-test using GraphPad Prism version 9.1.2 (GraphPad Software, Inc.). All experiments were repeated $\geq 3$ times. $\mathrm{P}<0.05$ was considered to indicate a statistically significant difference. The statistical significance of differences in the responses due to dose variation was evaluated by P-values for the interaction term of dose and treatment in a multiple linear regression model (SPSS 25; IBM Corp.).

\section{Results}

High mRNA expression of CD155/CD112 is a prognostic marker of poor OS in patients with AML. Analysis of gene expression profiles from patients with newly diagnosed AML deposited in TCGA revealed that high CD155/CD112 mRNA expression was significantly associated with poor OS $[\mathrm{n}=162$ (CD155/CD112 high group, $\mathrm{n}=11$; control group, $\mathrm{n}=151$ ); $\mathrm{P}=0.0471$; Fig. 1]. Therefore, expression of CD155 and CD112, novel immune checkpoints, may be novel biomarkers for poor OS in patients with AML.

CD155/CD112 expression is downregulated by trametinib in AML cells. The present study subsequently investigated how CD155/CD112 expression in AML cells can be manipulated. CD155 expression is induced by fibroblast growth factor via the Raf-MEK-ERK signaling pathway in NIH3T3 cells (21). It was hypothesized that CD155 expression could be suppressed by Raf-MEK-ERK signaling pathway inhibition in AML cells. The change in CD155 surface expression was investigated following treatment with trametinib, an MEK inhibitor, in AML cells with and without FLT3 mutation (22) and was shown to be suppressed by trametinib in all of the examined cell lines. In addition, CD112 surface expression was downregulated by trametinib in AML cells with or without FLT3 mutations (Fig. 2). However, no drug concentration-dependent changes were observed for CD155 expression in K562 cells or CD112 expression in NB4 cells. These results may be due to low expression of CD155 or CD112 at baseline. 
MOLM-13

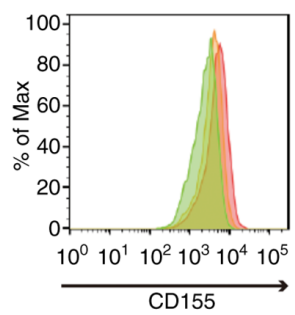

MV-4-11

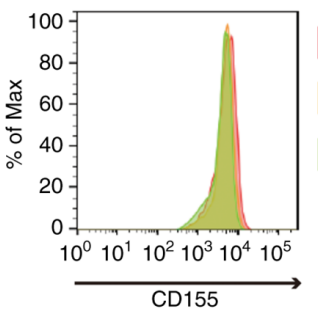

THP-1

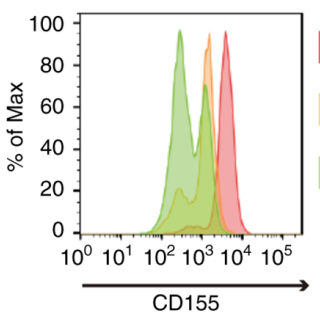

K562

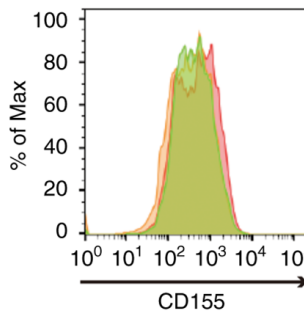

DMSO

Trametinib $10 \mathrm{nM}$

Trametinib $100 \mathrm{nM}$
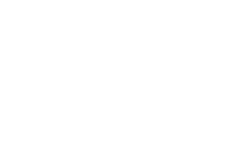

DMSO

Trametinib $10 \mathrm{nM}$

Trametinib $100 \mathrm{nM}$

NB-4

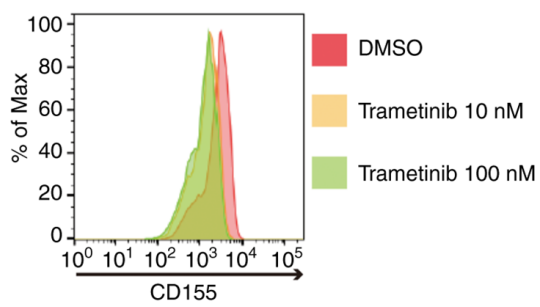

KG-1

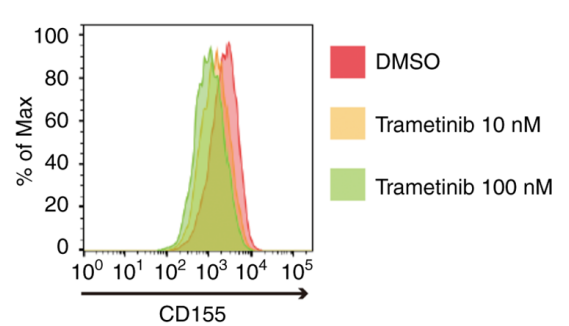

MFI

4238

3190

2168

MFI

4509

4259

3547

MFI

3273

865

443

MFI

40

309

383

MFI

2145

1210

1049

MFI

2040

1293

984
MOLM-13

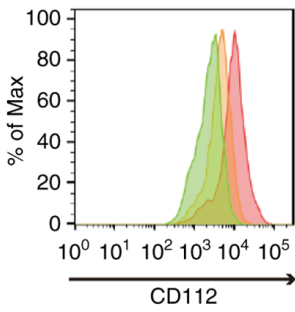

\section{DMSO}

Trametinib $10 \mathrm{nM}$

Trametinib $100 \mathrm{nM}$

2143

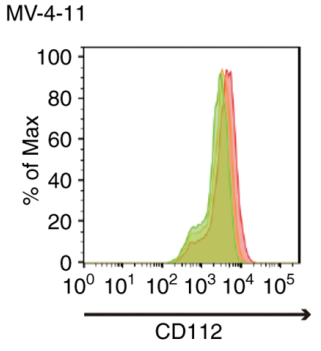

MFI

3311

2517

2065

THP-1

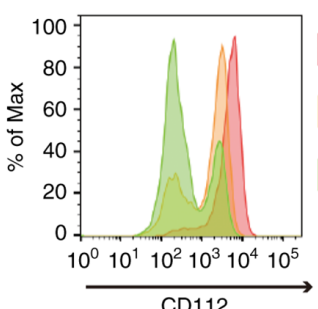

MFI

3999

1088

395

K562

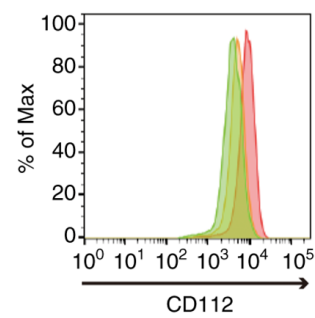

MFI

7345

4355

3426

NB-4

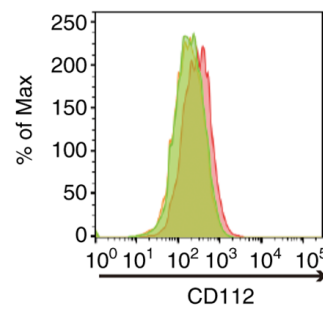

MFI

259

165

174

KG-1

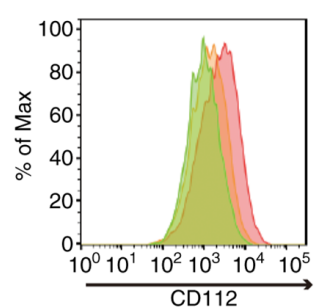

MF

DMSO

2133

Trametinib $10 \mathrm{nM}$

Trametinib $100 \mathrm{nM} \quad 918$

Figure 2. MEK inhibitor (trametinib) suppresses CD155 and CD112 surface expression of most AML cell lines (MOLM-13, MV-4-11, THP-1, KG-1) examined. Histograms of CD155 and CD112 expression in AML cell lines treated with trametinib (10 and $100 \mathrm{nM}$ : yellow and green, respectively)/DMSO (red) for 48 h. AML, acute myeloid leukemia; MFI, mean fluorescence intensity.

CD155 and CD112 mRNA expression is downregulated by FLT3 inhibitors in AML cells with FLT3 mutations. The Raf/MEK/ERK signaling pathway can be activated by mutations/amplifications of FLT3 kinase, and it is considered to be located downstream of the FLT3 signaling pathway (9). CD155 and CD112 downregulation by trametinib suggested 

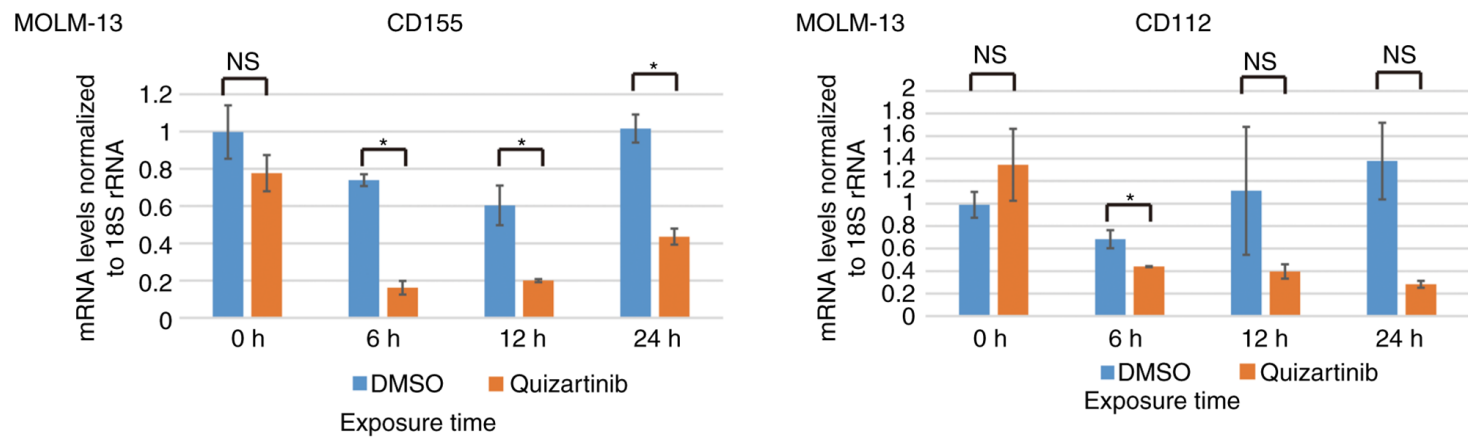

MV-4-11
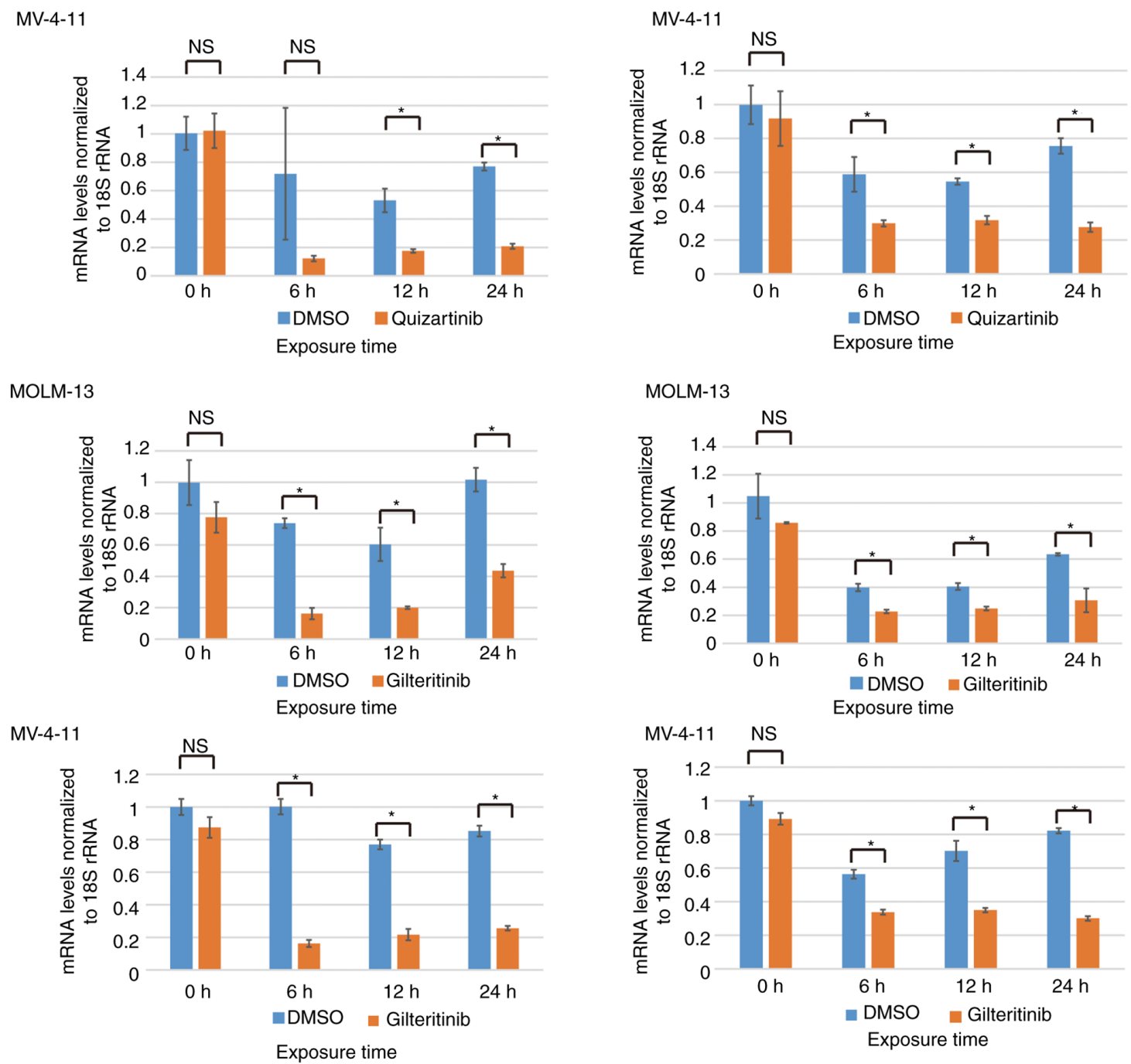

Figure 3. CD155 and CD112 mRNA expression is downregulated by FLT3 inhibitors in acute myeloid leukemia cells with FLT3 mutations. CD155 and CD112 mRNA expression levels in MOLM-13 and MV-4-11 cells exposed to FLT3 inhibitors (quizartinib or gilteritinib). Experiments were performed in triplicate. Data were statistically analyzed using the one-tailed unpaired t-test. "P<0.05. 18S rRNA, 18S ribosomal RNA; FLT3, FMS-like tyrosine kinase 3; NS, no significant difference.

the possibility of their downregulation by FLT3 inhibitors in AML cells containing FLT3-ITD mutations. The present study investigated the changes in CD155/CD112 mRNA expression after treatment of MOLM-13 and MV-4-11 cells with FLT3 inhibitors. Quizartinib is a type II FLT3 inhibitor, which targets only mutated FLT3 with an inactive conformation, whereas gilteritinib is a type I FLT3 inhibitor targeting mutated FLT3 with both active and inactive conformations (10). Quizartinib decreased CD155 mRNA expression in MOLM-13 (6, 12 and $24 \mathrm{~h})$ and MV-4-11 cells (12 and $24 \mathrm{~h}$ ). Quizartinib decreased CD112 mRNA expression in MOLM-13 (6 h) and MV-4-11 cells $(6,12$ and $24 \mathrm{~h})$. Gilteritinib decreased CD155 mRNA expression in MOLM-13 (6, 12 and 24 h) and MV-4-11 cells (6, 12 and 24 h). Gilteritinib decreased CD112 mRNA expression in MOLM-13 (6, 12 and $24 \mathrm{~h})$ and MV-4-11 cells (6, 12 and 24 h; Fig. 3).

FLT3 mutation-specific downregulation of CD155 and CD112 surface expression in AML cells by FLT3 inhibitors. As shown 
MOLM-13

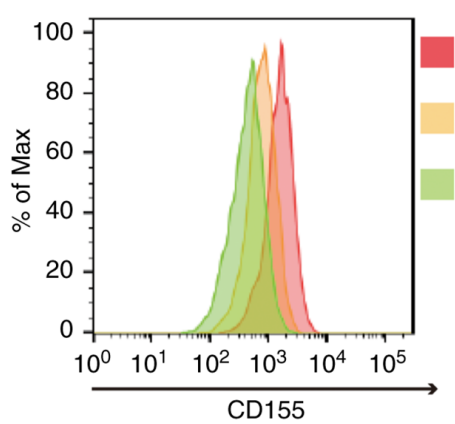

DMSO

Quizartinib $1 \mathrm{nM} 705$

Quizartinib 10 nM 339

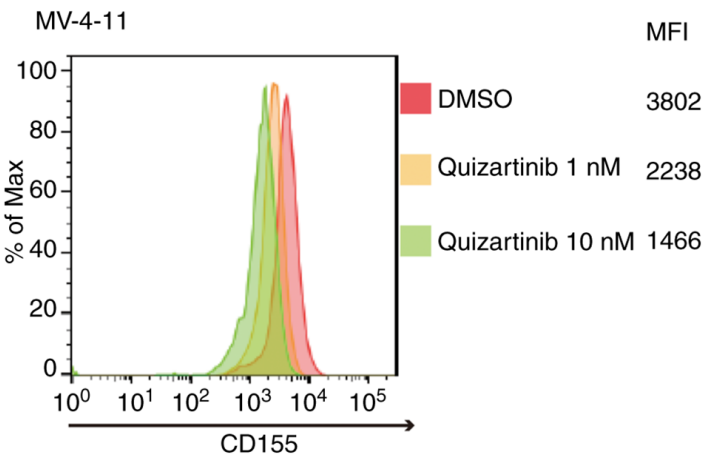

MOLM-13
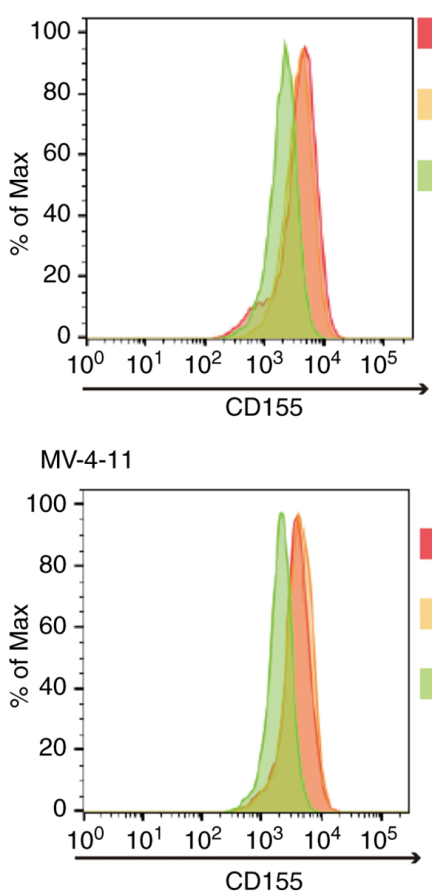

MFI

401

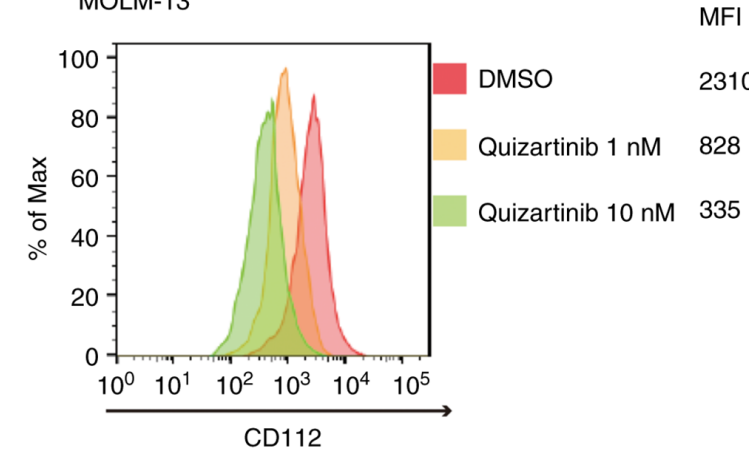

MV-4-11

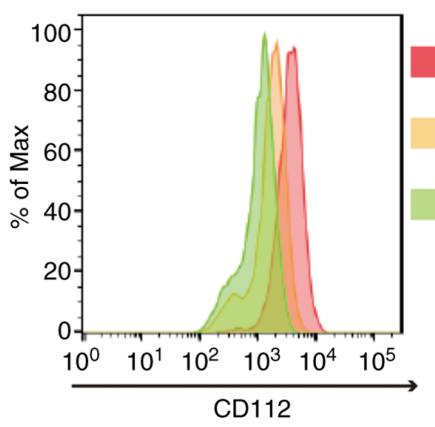

DMSO

Quizartinib $1 \mathrm{nM} 1557$

Quizartinib $10 \mathrm{nM} 1040$
DMSO

Gilteritinib 1 nM 3339

Gilteritinib 10 nM 1898

MFI

3337

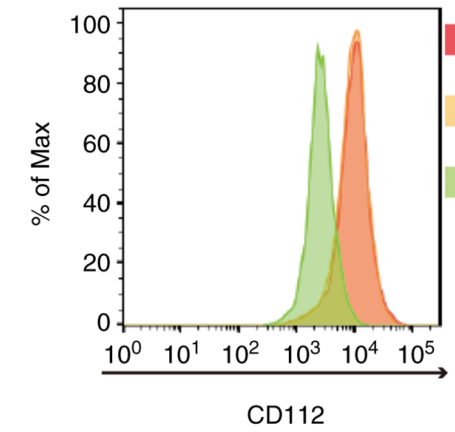

MV-4-11

DMSO

MFI

Gilteritinib 1 nM 3754

Gilteritinib 10 nM 1905

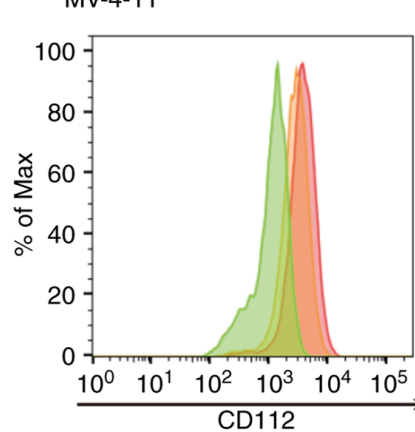

MFI

DMSO

3461

Gilteritinib 1 nM 2574

Gilteritinib 10 nM 1094

Figure 4. FLT3 inhibitor (quizartinib and gilteritinib) treatment suppresses CD155 and CD112 surface expression in acute myeloid leukemia cell lines with FLT3 mutations. Histograms of CD155 and CD112 expression in MOLM-13 and MV-4-11 cells treated with quizartinib or gilteritinib (1 and $10 \mathrm{nM}$ : yellow and green, respectively)/DMSO (red) for 48 h. FLT3, FMS-like tyrosine kinase 3; MFI, mean fluorescence intensity.

in Fig. 4, quizartinib and gilteritinib downregulated CD155 and CD112 surface expression in both MOLM-13 and MV-4-11 cells. By contrast, the treatment of AML cells without FLT3 mutations, including THP-1, K562 and NB-4 cells, with quizartinib or gilteritinib did not affect the surface expression of CD155 and CD112 (Fig. 5). These results suggested that downregulation of CD155 and CD112 surface expression in AML cells by FLT3 inhibitors is dependent on the presence of FLT3 mutations.
TIGIT expression in NK and $\gamma \delta T$ cells. The present study subsequently examined how CD155 and CD112 downregulation in AML cells under FLT3 inhibition affects the cytotoxic effects of effector cells, including NK and T cells. Poor OS in patients with AML with high CD155 and CD112 expression in leukemic cells indicates that the interaction between TIGIT and CD155/CD112 blocks the cytotoxicity of effector cells. To test our hypothesis, TIGIT expression in NK cells was 

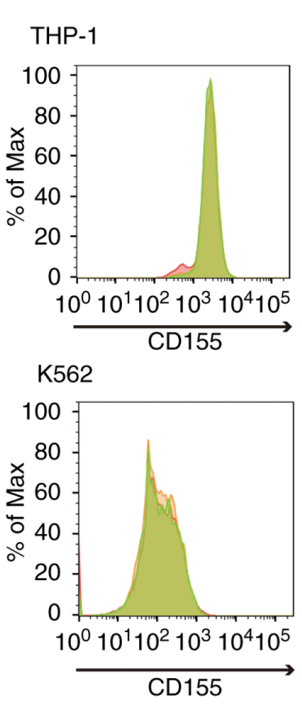

\begin{tabular}{ll} 
DMSO & 2145 \\
\hline Quizartinib 1 nM & 2406 \\
\hline Quizartinib 10 nM & 2398
\end{tabular}

NB-4

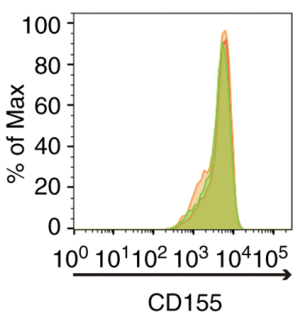

THP-1

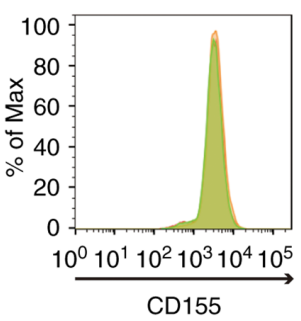

K562
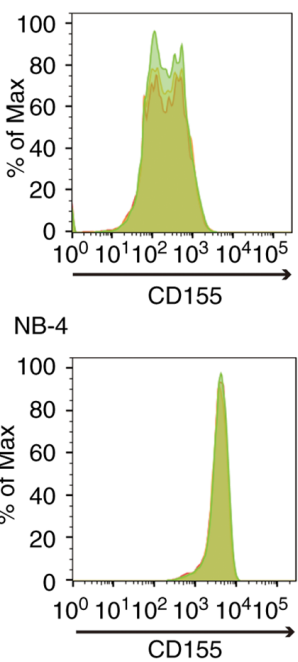

DMSO

Quizartinib $1 \mathrm{nM}$

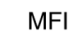

Quizartinib $1 \mathrm{nM} \quad 3629$

Quizartinib $10 \mathrm{nM}$

3724

DMSO

Gilteritinib $1 \mathrm{nM}$

Gilteritinib 10 nM

MFI

2795

3047

\section{DMSO}

Gilteritinib $1 \mathrm{nM}$

Gilteritinib $10 \mathrm{nM}$

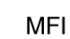

\section{DMSO}

Gilteritinib $1 \mathrm{nM}$

3382

3359

Gilteritinib 10 nM

$$
\text { THP-1 }
$$

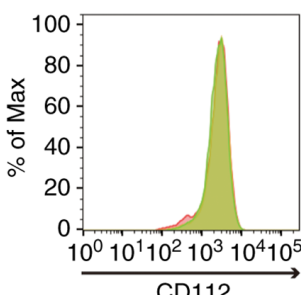

DMSO

Quizartinib $1 \mathrm{nM}$

Quizartinib $10 \mathrm{nM}$

2290

Quizartinib $10 \mathrm{nM}$

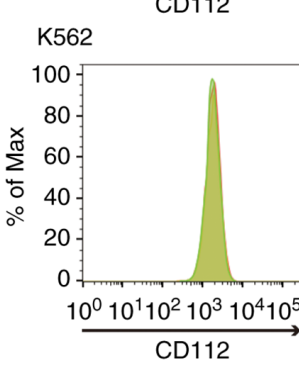

MFI

1689

Quizartinib $1 \mathrm{nM}$

1659

Quizartinib $10 \mathrm{nM}$

1634

MFI

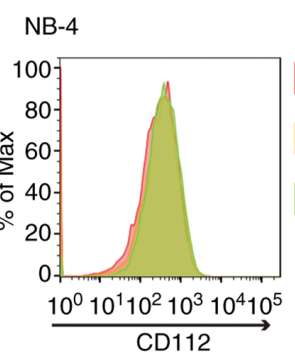

DMSO

Quizartinib $1 \mathrm{nM}$

Quizartinib 10 nM

THP-1

MFI

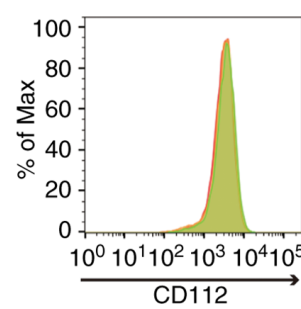

DMSO

Gilteritinib $1 \mathrm{nM}$

2732

K562

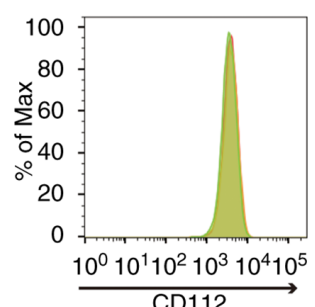

Gilteritinib $10 \mathrm{nM}$

NB-4
DMSO

Gilteritinib $1 \mathrm{nM}$

Gilteritinib 10 nM
MFI

3479

3543

3243

MFI

332

319

331

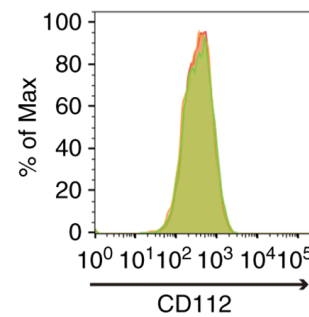

Figure 5. FLT3 inhibitor (quizartinib and gilteritinib) treatment does not suppress CD155 and CD112 surface expression in acute myeloid leukemia cell lines without FLT3 mutations. Histograms of CD155 and CD112 expression in THP-1, K562 and NB-4 cells treated with quizartinib or gilteritinib (1 and 10 nM: yellow and green, respectively)/DMSO (red) for 48 h. FLT3, FMS-like tyrosine kinase 3; MFI, mean fluorescence intensity.

analyzed. KHYG-1 is a cell line derived from human primary NK cells (23), and flow cytometric analysis revealed that $81.4 \%$ of the cells were positive for TIGIT (Fig. 6A). Furthermore,
TIGIT expression in KHYG-1 cells was unaffected by FLT3 inhibition by flow cytometry $(85.1 \%) . \gamma \delta \mathrm{T}$ cells are $\mathrm{CD} 3^{+} \mathrm{Vd} 2^{+}$ and highly cytotoxic, and the activation of $\gamma \delta \mathrm{T}$ cells does 
A

KHYG-1 DMSO

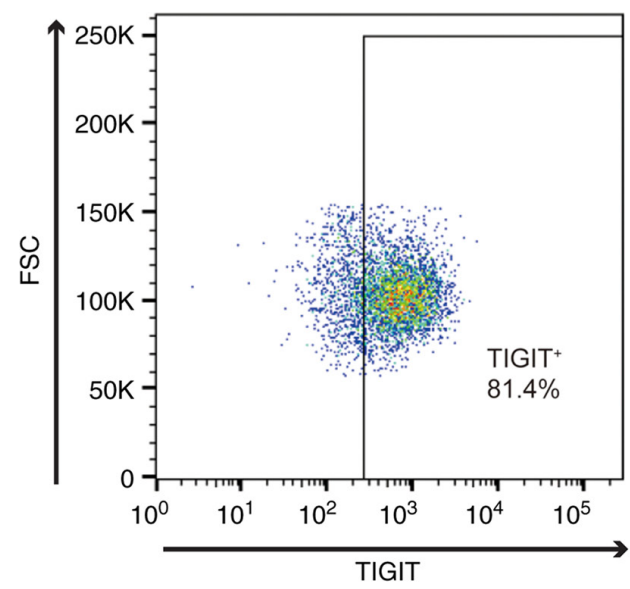

B

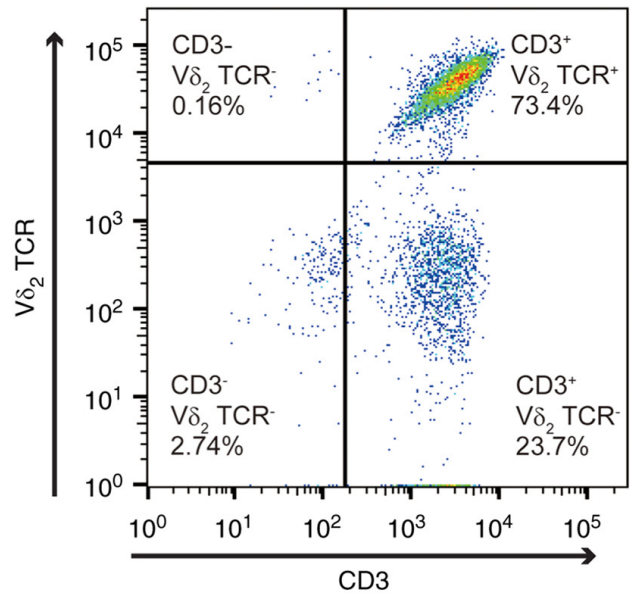

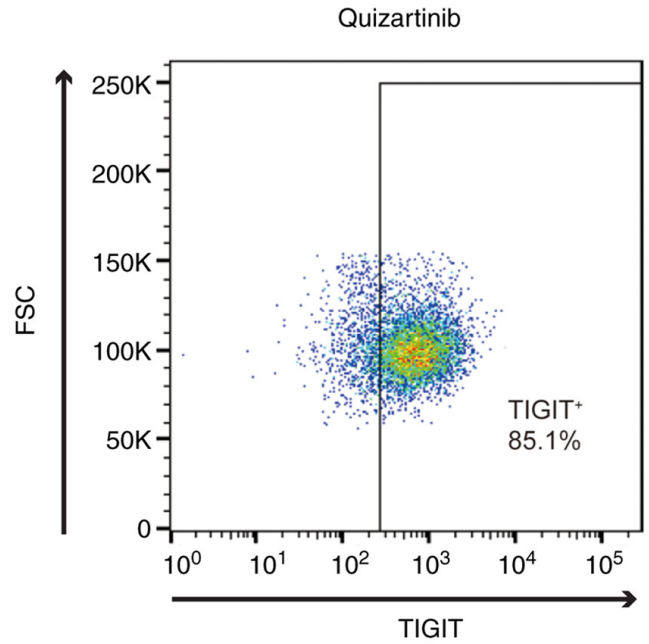

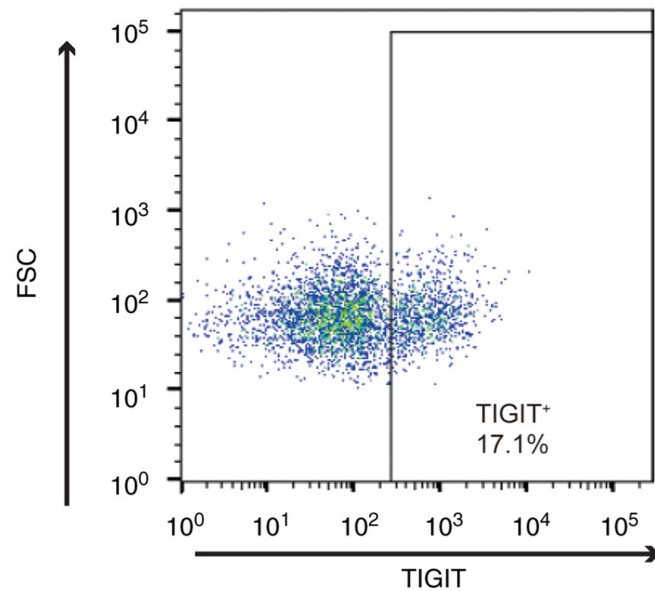

Figure 6. TIGIT expression in natural killer and $\gamma \delta$ T cells. (A) FMS-like tyrosine kinase 3 inhibitor (quizartinib) did not change TIGIT surface expression in KHYG-1 cells. (B) TIGIT surface expression in $\gamma \delta \mathrm{T}$ cells (CD3+ V82+). Left, separation of $\gamma \delta \mathrm{T}$ cells; right, TIGIT expression of isolated $\gamma \delta \mathrm{T}$ cells. FSC, forward scatter; TCR, T cell receptor; TIGIT, T cell immunoglobulin and immunoreceptor tyrosine-based inhibitory motif domain.

not necessarily depend on major histocompatibility complex antigen presentation, which makes $\gamma \delta \mathrm{T}$ cells a promising target for allogeneic cell transfer therapy $(16,24)$. Flow cytometric analysis of $\gamma \delta$ T cells revealed that TIGIT expression was restricted in $17.1 \%$ of the analyzed cells (Fig. 6B).

Enhanced ADCC activity of daratumumab following FLT3 inhibitor treatment in AML cells with FLT3-ITD mutations. As shown in Fig. 6A, 81.4\% of the analyzed KHYG-1 cells were positive for TIGIT. These results suggested the possibility that cytotoxicity of KYHG-1 cells against AML cells with FLT3-ITD mutations treated with FLT3 inhibitors could be affected by the reduction of CD155/CD112. Daratumumab is a therapeutic antibody for multiple myeloma with ADCC activity that targets CD38 expressed in myeloma cells (25). The present study demonstrated CD38 expression in MV-4-11 and MOLM-13 cells (Fig. 7A) and analyzed the ADCC activity of daratumumab in these cells with or without treatment with quizartinib. In both MV-4-11 and MOLM-13 cells, the ADCC activity of daratumumab was enhanced by FLT3 inhibition (Fig. 7B). Conversely, the ADCC activity of daratumumab was unaffected in THP-1 cells without FLT3 mutations under FLT3 inhibition (Fig. 7C). These results suggested that the suppression of anti-leukemic activity of NK cells is mediated by the interaction between CD155/CD112 and TIGIT, which is de-repressed by FLT3 inhibition in AML cells with FLT3 mutations.

Enhancement of direct activity of NK cells and ADCC activity of primary NK cells against AML cells with FLT3-ITD mutations under FLT3 inhibition. The direct cytotoxicity of KHYG-1 cells against MOLM-13 and MV-4-11 cells under FLT3 inhibition was investigated. Direct activity was confirmed in both cell lines. In MOLM-13 cells, direct activity was enhanced, but this was not significant. In MV-4-11 cells, direct activity was significantly enhanced under FLT3 inhibition (Fig. 8A). Primary NK cells were purified from peripheral blood and the ADCC activity of primary NK cells against AML cells with FLT3 mutations under FLT3 inhibition was estimated. The ADCC of primary NK cells against MOLM-13 and MV-4-11 cells was also enhanced by FLT3 inhibition (Fig. 8B).

$\gamma \delta$ T cell cytotoxicity against AML cells with FLT3 mutations is not enhanced by FLT3 inhibition. As shown in Fig. 6B, TIGIT-positive rate (17.1\%) of $\gamma \delta \mathrm{T}$ cells was lower than that of 
A

MOLM-13

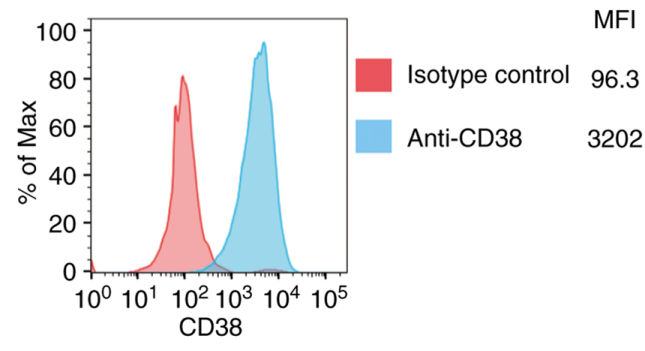

B Target cell: MOLM-13

Effector cell: KHYG-1/CD16

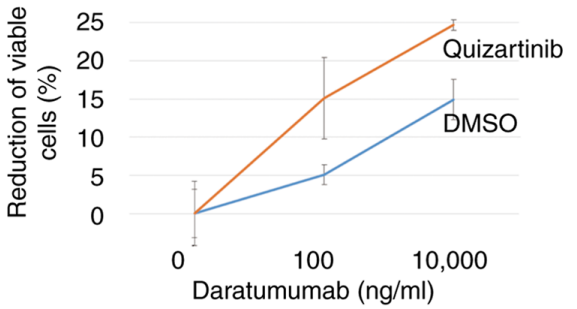

C Target cell: THP-1

Effector cell: KHYG-1/CD16

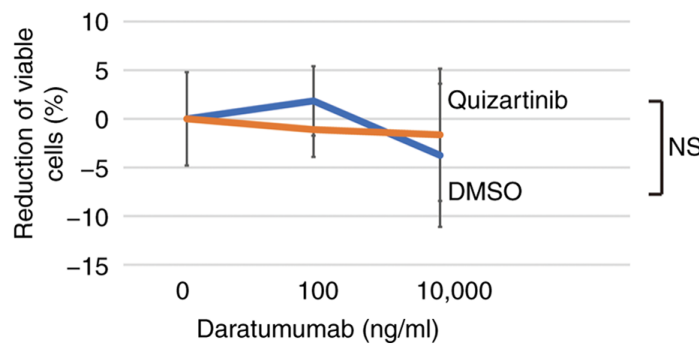

MV-4-11

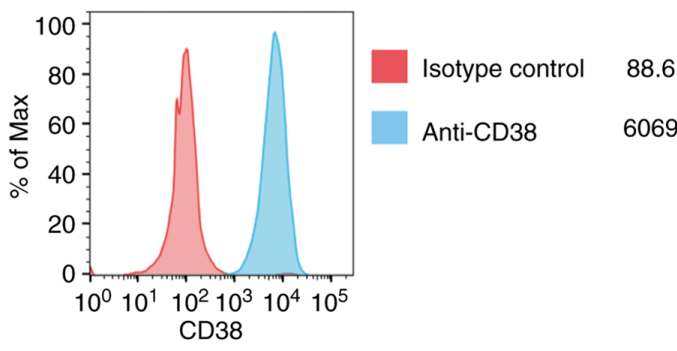

Target cell: MV-4-11

Effector cell: KHYG-1/CD16

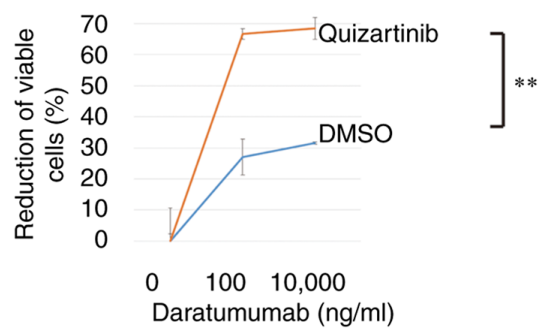

Figure 7. Enhanced ADCC activity of daratumumab following FLT3 inhibitor treatment in AML cells with FLT3-internal tandem duplication. (A) Histograms of CD38 expression in MOLM-13 and MV-4-11 cells. (B) ADCC assay of daratumumab. Target cells (MOLM-13 and MV-4-11) were exposed to quizartinib or DMSO for $48 \mathrm{~h}$ before coculture with KHYG-1/CD16 cells. (C) ADCC assay of daratumumab. Target cells (THP-1) were exposed to quizartinib or DMSO for $48 \mathrm{~h}$ before coculture with KHYG-1/CD16 cells. Experiments were repeated thrice. Error bars represent the SD. The data were statistically analyzed using a multiple linear regression model. ${ }^{* *} \mathrm{P}<0.01$. ADCC, antibody-dependent cellular cytotoxicity; FLT3, FMS-like tyrosine kinase 3; MFI, mean fluorescence intensity; NS, no significant difference.

KHYG-1 cells (81.4\%). The cytotoxicity of $\gamma \delta$ T cells against AML cells with FLT3-ITD mutations was assessed. The cytotoxicity was significantly diminished by FLT3 inhibition (Fig. 8C).

\section{Discussion}

The present study suggested that CD155 and CD112 expression in AML cells with FLT3-ITD mutations was decreased, and cytotoxicity against these cells by NK cells was enhanced following FLT3 inhibition. The possibility of CD155 and CD112 as biomarkers of poor OS in patients with AML was also suggested.

CD155 and CD112 are immune checkpoints, and the involvement of increased expression of immune checkpoints in poor prognosis of AML has been reported (26). B7-H2 positivity in leukemic cells has a strong prognostic value for shorter survival (27). Higher expression of the checkpoint molecules cytotoxic T-lymphocyte associated protein 4, PD-1 and lymphocyte activating 3 in leukemic cells compared with patients with normal prognosis is also a marker of poor prognosis (28). As for the association between prognosis and specific mutations found in AML, the expression of PD-1 ligand PD-L1 is increased in hematopoietic stem cells of patients with TP53 mutations (29). A recent study analyzed the expression of immune checkpoints in $\mathrm{NK}$ cells from patients with AML and found that PD-1, TIGIT and T cell immunoglobulin and mucin-domain containing-3 expression are increased in these cells compared with those from healthy donors (30). Furthermore, a high frequency of TIGIT ${ }^{+} \mathrm{NK}$ cells is associated with a poor prognosis in patients with AML (30). To the best of our knowledge, the present study was the first to report the expression of TIGIT ligands as a marker of poor prognosis in AML as well as a target of FLT3 inhibition.

Although therapies using FLT3 inhibitors have improved the historically poor outcomes of FLT3-mutated AML, the clinical response to an FLT3 inhibitor is temporary in most cases of relapse/refractory disease (31). Resistance to FLT3 inhibitors is derived from a number of mechanisms, including inherent mutations insensitive to FLT3 inhibitors, acquisition of mutations in the ATP-binding pocket and activation of alternative survival pathways (32). Enhancement of allogeneic immunity has received attention as a strategy to overcome 
A

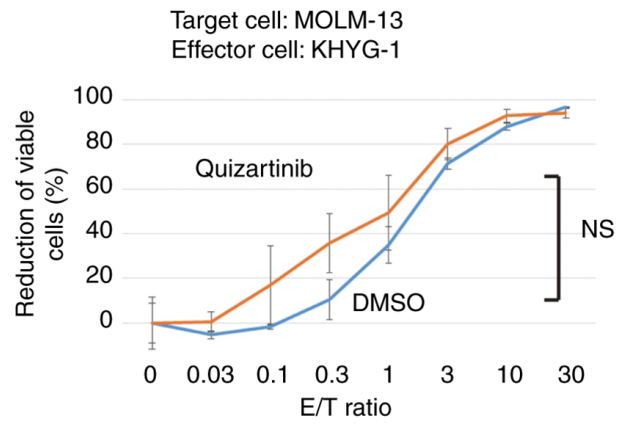

B

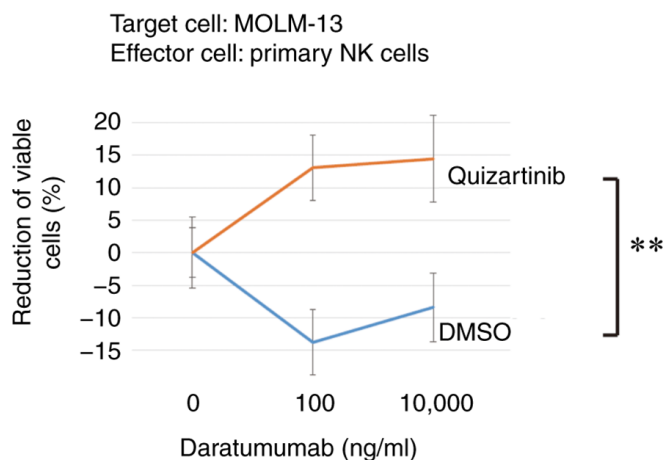

C

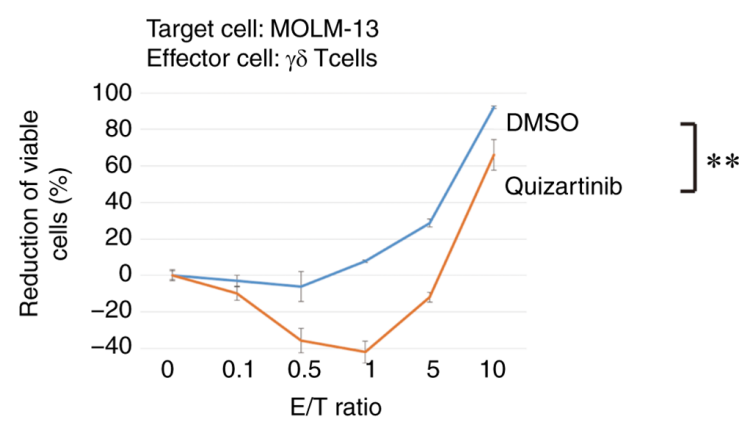

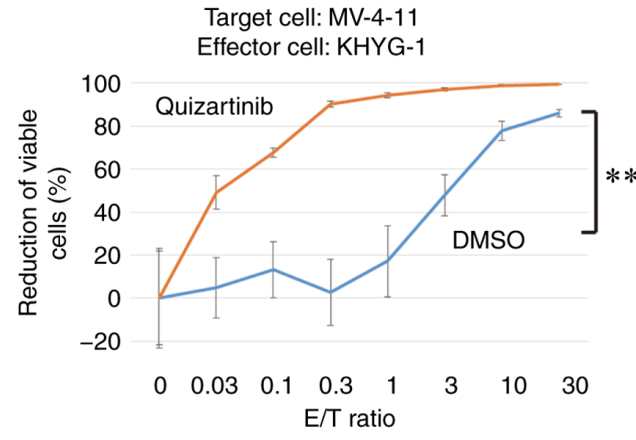

Target cell: MV-4-11

Effector cell: primary NK cells

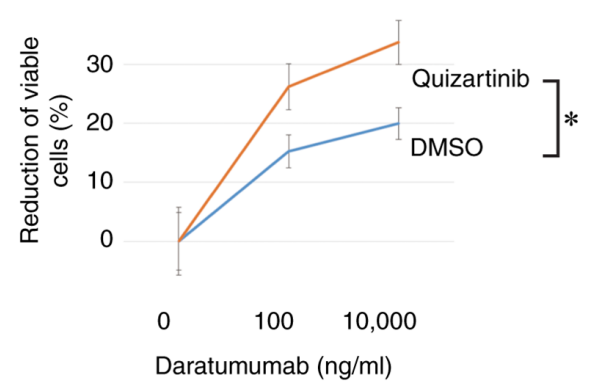

Target cell: MV-4-11

Effector cell: $\gamma \delta$ Tcells

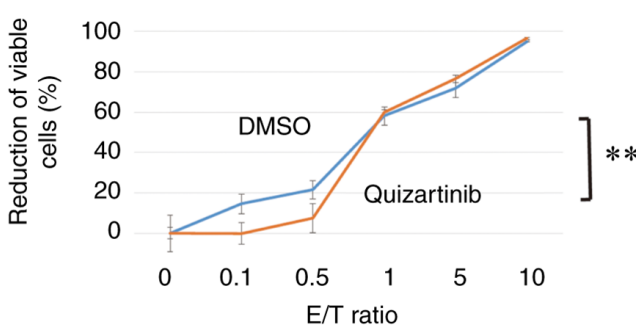

Figure 8. KHYG-1 cell direct cytotoxicity against AML cells with FLT3 mutations and ADCC of primary NK cells against MOLM-13 and MV-4-11 cells are enhanced under FLT3 inhibition. $\gamma \delta$ T cell cytotoxicity against AML cells with FLT3 mutations was not enhanced under FLT3 inhibition. (A) NK cell direct cytotoxicity assay. Target cells (MOLM-13 and MV-4-11) were exposed to quizartinib or DMSO for $48 \mathrm{~h}$ before coculture with KHYG-1 cells at various E/T ratios (0-30). (B) ADCC assay of daratumumab. Target cells (MOLM-13 and MV-4-11) were exposed to quizartinib or DMSO for 48 h before coculture with KHYG-1/CD16 cells. (C) $\gamma \delta \mathrm{T}$ cell direct cytotoxicity assay. Target cells (MOLM-13 and MV-4-11) were exposed to quizartinib or DMSO for 48 h before coculture with $\gamma \delta \mathrm{T}$ cells at various E/T ratios (0-10). All experiments were repeated thrice. Error bars represent the SD. Data were statistically analyzed using a multiple linear regression model. ${ }^{*} \mathrm{P}<0.05 ;{ }^{* *} \mathrm{P}<0.01$. ADCC, antibody-dependent cellular cytotoxicity; AML, acute myeloid leukemia; E/T, effector/tumor; FLT3, FMS-like tyrosine kinase 3; NK, natural killer; NS, no significant difference.

resistance. Increased activity of sorafenib, an FLT3 inhibitor, which synergizes with allogeneic SCT in FLT3-ITD-positive AML suggests the possibility of alloimmune effects to overcome the resistance to FLT3 inhibitors (33). Furthermore, it has been reported that promotion of graft-vs.-leukemia activity by sorafenib through IL-15 production in FLT3-ITD mutant leukemia has the potential to cure FLT3-ITD AML (34).

In addition to allogeneic immunity, the inhibition of immune evasion mediated by immune checkpoints is expected to have a cytotoxic effect (35). The response of leukemic cells to $\mathrm{T}$ cell activation leads to the downregulation of $\mathrm{T}$ cell costimulatory ligand $\mathrm{B} 7-\mathrm{H} 2$ along with the upregulation of coinhibitory ligand PD-L1 to shut down T cell activation (36). It was hypothesized that this immune phenotypic switch would cause immune evasion by AML cells.

The association of DNAM-1/TIGIT, another immune checkpoint, with immune evasion has been mainly reported in T cells (37). In addition to the presence of high frequencies of $\mathrm{CD}^{+} \mathrm{T}$ cells expressing TIGIT in patients with FLT3-ITD mutations, a decrease in CD226 ${ }^{+} \gamma \delta \mathrm{T}$ cells and an increase in TIGIT $^{+} \gamma \delta \mathrm{T}$ cells in patients with de novo AML have been reported (38). It has also been reported that TIGIT-DNAM-1 ${ }^{+}$ $\gamma \delta \mathrm{T}$ cells are restored in patients with AML who achieve complete remission after chemotherapy. Furthermore, the high expression of TIGIT ${ }^{+}$DNAM-1- in $\gamma \delta$ T cells may be a biomarker of poor OS (38).

As for the anti-leukemic effect of NK cells, relapse prevention by killer cell immunoglobulin-like receptor (KIR)-mismatched NK cells in allogeneic SCT (KIR mismatched) has been reported (1). However, to the best of our knowledge, the role of immune checkpoints in NK cells has not been previously described in patients with AML. The results of the present study indicated the possible usefulness of blocking the interaction between CD155/CD112 and TIGIT 
for NK cell therapy and the inhibitory role of TIGIT in the anti-leukemic effect of NK cells.

The lower effect of CD155/CD112 downregulation on the anti-leukemic effect of $\gamma \delta \mathrm{T}$ cells compared with NK cells was considered to be due to low TIGIT expression in $\gamma \delta \mathrm{T}$ cells. As previously described, TIGIT $^{+} \gamma \delta$ T cells are increased in patients with de novo AML, and there is a possibility that CD155 and CD112 downregulation by FLT3 inhibitors in FLT3-mutated AML cells may stimulate the cytotoxicity of $\gamma \delta$ T cells in these patients (38).

In conclusion, the present study revealed that CD155 and CD112 downregulation in AML cells by FLT3 inhibitors is dependent on FLT3 mutations. Although the treatment of AML cells with trametinib also reduced CD155 and CD112 expression, the downregulation was independent of FLT3 mutations. In addition, the cytotoxic effect of FLT3 inhibitors was restricted to AML cells with FLT3 mutations. Therefore, blocking immune evasion through CD155 and CD112 downregulation by FLT3 inhibitors is expected to lead to therapeutic effects with fewer side effects compared with the use of trametinib in patients with FLT3 mutations. The present finding that FLT3 inhibitors displayed cytotoxic effects as well as enhanced NK cell activity suggested the possible usefulness of FLT3 inhibitors in combination with adaptive NK cell therapy as a novel strategy for immunotherapy of AML.

\section{Acknowledgements}

Quizartinib was provided by Daiichi Sankyo Co.,Ltd., Tokyo, Japan.

\section{Funding}

The present study was funded by Japan Society for the Promotion of Science Kagaku Kenkyu hi (grant no. 20K08726).

\section{Availability of data and materials}

All data generated or analyzed during this study are included in this published article.

\section{Authors' contributions}

YK, MN and YI performed the research, analyzed and interpreted the data, and wrote the manuscript. YI designed the research and edited the manuscript. $\mathrm{MH}, \mathrm{MF}, \mathrm{HT}$ and AT analyzed and interpreted the data and revised the manuscript. YI supervised the projects. YK and YI confirm the authenticity of all the raw data. All authors have read and approved the final manuscript.

\section{Ethics approval and consent to participate}

The present study was approved by the Institutional Review Board at the Institute of Medical Science of the University of Tokyo (approval no. 30-72-A0222; Tokyo, Japan). Primary cells derived from the patients who signed informed consent form were used.

\section{Patient consent for publication}

Not applicable.

\section{Competing interests}

The authors declare that they have no competing interests.

\section{References}

1. Ruggeri L, Capanni M, Urbani E, Perruccio K, Shlomchik WD, Tosti A, Posati S, Rogaia D, Frassoni F, Aversa F, et al: Effectiveness of donor natural killer cell alloreactivity in mismatched hematopoietic transplants. Science 295: 2097-2100, 2002.

2. Paczulla AM, Rothfelder K, Raffel S, Konantz M, Steinbacher J, Wang H, Tandler C, Mbarga M, Schaefer T, Falcone M, et al: Absence of NKG2D ligands defines leukaemia stem cells and mediates their immune evasion. Nature 572: 254-259, 2019.

3. Sanchez-Correa B, Valhondo I, Hassouneh F, Lopez-Sejas N, Pera A, Bergua JM, Arcos MJ, Bañas H, Casas-Avilés I, Durán E, et al: DNAM-1 and the TIGIT/PVRIG/TACTILE Axis: Novel immune checkpoints for natural killer cell-based cancer immunotherapy. Cancers (Basel) 11: 877, 2019.

4. Long EO, Kim HS, Liu D, Peterson ME and Rajagopalan S: Controlling natural killer cell responses: Integration of signals for activation and inhibition. Annu Rev Immunol 31: 227-258, 2013.

5. Pende D, Spaggiari GM, Marcenaro S, Martini S, Rivera P, Capobianco A, Falco M, Lanino E, Pierri I, Zambello R, et al: Analysis of the receptor-ligand interactions in the natural killer-mediated lysis of freshly isolated myeloid or lymphoblastic leukemias: Evidence for the involvement of the poliovirus receptor (CD155) and nectin-2 (CD112). Blood 105: 2066-2073, 2005.

6. Tahara-Hanaoka S, Shibuya K, Onoda Y, Zhang H, Yamazaki S, Miyamoto A, Honda S, Lanier LL and Shibuya A: Functional characterization of DNAM-1 (CD226) interaction with its ligands PVR (CD155) and nectin-2 (PRR-2/CD112). Int Immunol 16: 533-538, 2004.

7. Stanietsky N, Simic H, Arapovic J, Toporik A, Levy O, Novik A, Levine Z, Beiman M, Dassa L, Achdout H, et al: The interaction of TIGIT with PVR and PVRL2 inhibits human NK cell cytotoxicity. Proc Natl Acad Sci USA 106: 17858-17863, 2009.

8. Gilliland DG and Griffin JD: The roles of FLT3 in hematopoiesis and leukemia. Blood 100: 1532-1542, 2002.

9. Steelman LS, Abrams SL, Whelan J, Bertrand FE, Ludwig DE, Bäsecke J, Libra M, Stivala F, Milella M, Tafuri A, et al: Contributions of the Raf/MEK/ERK,PI3K/PTEN/Akt/mTOR and Jak/STAT pathways to leukemia. Leukemia 22: 686-707, 2008.

10. Daver N, Schlenk RF, Russell NH and Levis MJ: Targeting FLT3 mutations in AML: Review of current knowledge and evidence. Leukemia 33: 299-312, 2019.

11. Fischer T, Stone RM, Deangelo DJ, Galinsky I, Estey E, Lanza C, Fox E, Ehninger G, Feldman EJ, Schiller GJ, et al: Phase IIB trial of oral Midostaurin (PKC412), the FMS-like tyrosine kinase 3 receptor (FLT3) and multi-targeted kinase inhibitor, in patients with acute myeloid leukemia and high-risk myelodysplastic syndrome with either wild-type or mutated FLT3. J Clin Oncol 28: 4339-4345, 2010.

12. Wander SA, Levis MJ and Fathi AT: The evolving role of FLT3 inhibitors in acute myeloid leukemia: Quizartinib and beyond. Ther Adv Hematol 5: 65-77, 2014.

13. Perl AE, Martinelli G, Cortes JE, Neubauer A, Berman E, Paolini S, Montesinos P, Baer MR, Larson RA, Ustun C, et al: Gilteritinib or chemotherapy for relapsed or refractory FLT3-mutated AML. N Engl J Med 381: 1728-1740, 2019.

14. Cortes JE, Khaled S, Martinelli G, Perl AE, Ganguly S, Russell N, Krämer A, Dombret H, Hogge D, Jonas BA, et al: Quizartinib versus salvage chemotherapy in relapsed or refractory FLT3-ITD acute myeloid leukaemia (QuANTUM-R): A multicentre, randomised, controlled, open-label, phase 3 trial. Lancet Oncol 20: 984-997, 2019.

15. Wang M, Bu J, Zhou M, Sido J, Lin Y, Liu G, Lin Q, Xu X, Leavenworth JW and Shen E: $\mathrm{CD}^{+} \mathrm{T}$ cells expressing both PD-1 and TIGIT but not CD226 are dysfunctional in acute myeloid leukemia (AML) patients. Clin Immunol 190: 64-73, 2018.

16. Cui Q, Shibata H, Oda A, Amou H, Nakano A, Yata K, Hiasa M, Watanabe K, Nakamura S, Miki H, et al: Targeting myeloma-osteoclast interaction with $\mathrm{V} \gamma 9 \mathrm{~V} \delta 2 \mathrm{~T}$ cells. Int J Hematol 94: 63-70, 2011.

17. Futami M, Suzuki K, Kato S, Ohmae S, Tahara Y, Nojima M, Imai Y, Mimura T, Watanabe Y and Tojo A: The novel multi-cytokine inhibitor TO-207 specifically inhibits pro-inflammatory cytokine secretion in monocytes without affecting the killing ability of CAR T cells. PLoS One 15: e0231896, 2020. 
18. Bai Y, Soda Y, Izawa K, Tanabe T, Kang X, Tojo A, Hoshino H, Miyoshi H, Asano S and Tani K: Effective transduction and stable transgene expression in human blood cells by a third-generation lentiviral vector. Gene Ther 10: 1446-1457, 2003.

19. Livak KJ and Schmittgen TD: Analysis of relative gene expression data using real-time quantitative PCR and the 2(-Delta Delta C(T)) method. Methods 25: 402-408, 2001.

20. Cancer Genome Atlas Research Network; Ley TJ, Miller C, Ding L, Raphael BJ, Mungall AJ, Robertson A, Hoadley K, Triche TJ Jr, Laird PW, et al: Genomic and epigenomic landscapes of adult de novo acute myeloid leukemia. N Engl J Med 368: 2059-2074, 2013

21. Hirota T, Irie K, Okamoto R, Ikeda W and Takai Y: Transcriptional activation of the mouse Necl-5/Tage4/PVR/CD155 gene by fibroblast growth factor or oncogenic Ras through the Raf-MEK-ERK-AP-1 pathway. Oncogene 24: 2229-2235, 2005.

22. Quentmeier H, Reinhardt J, Zaborski M and Drexler HG: FLT3 mutations in acute myeloid leukemia cell lines. Leukemia 17: 120-124, 2003.

23. Yagita $M$, Huang $C L$, Umehara $H$, Matsuo $Y$, Tabata R, Miyake M, Konaka Y and Takatsuki K: A novel natural killer cell line (KHYG-1) from a patient with aggressive natural killer cell leukemia carrying a p53 point mutation. Leukemia 14: 922-930, 2000.

24. Deseke M and Prinz I: Ligand recognition by the $\gamma \delta$ TCR and discrimination between homeostasis and stress conditions. Cell Mol Immunol 17: 914-924, 2020.

25. Hirano M, Imai Y, Kaito Y, Murayama T, Sato K, Ishida T, Yamamoto J, Ito T, Futami M, Ri M, et al: Small-molecule HDAC and Akt inhibitors suppress tumor growth and enhance immunotherapy in multiple myeloma. J Exp Clin Cancer Res 40: 110, 2021.

26. Stamm H, Klingler F, Grossjohann EM, Muschhammer J, Vettorazzi E, Heuser M, Mock U, Thol F, Vohwinkel G, Latuske E, et al: Immune checkpoints PVR and PVRL2 are prognostic markers in AML and their blockade represents a new therapeutic option. Oncogene 37: 5269-5280, 2018.

27. Tamura H, Dan K, Tamada K, Nakamura K, Shioi Y, Hyodo H, Wang SD, Dong H, Chen L and Ogata K: Expression of functional B7-H2 and B7.2 costimulatory molecules and their prognostic implications in de novo acute myeloid leukemia. Clin Cancer Res 11: 5708-5717, 2005.

28. Dao FT, Wang J, Yang L and Qin YZ: Development of a poor-prognostic-mutations derived immune prognostic model for acute myeloid leukemia. Sci Rep 11: 4856, 2021.
29. Sallman DA, McLemore AF, Aldrich AL, Komrokji RS, McGraw KL, Dhawan A, Geyer S, Hou HA, Eksioglu EA, Sullivan A, et al: TP53 mutations in myelodysplastic syndromes and secondary AML confer an immunosuppressive phenotype. Blood 136: 2812-2823, 2020.

30. Liu G, Zhang Q, Yang J, Li X, Xian L, Li W, Lin T, Cheng J, Lin Q, Xu X, et al: Increased TIGIT expressing NK cells with dysfunctional phenotype in AML patients correlated with poor prognosis. Cancer Immunol Immunother: Jun 15, 2021 (Epub ahead of print)

31. Antar AI, Otrock ZK, Jabbour E, Mohty M and Bazarbachi A: FLT3 inhibitors in acute myeloid leukemia: Ten frequently asked questions. Leukemia 34: 682-696, 2020.

32. Chu SH and Small D: Mechanisms of resistance to FLT3 inhibitors. Drug Resist Updat 12: 8-16, 2009.

33. Metzelder SK, Schroeder T, Finck A, Scholl S, Fey M, Götze K, Linn YC, Kröger M, Reiter A, Salih HR, et al: High activity of sorafenib in FLT3-ITD-positive acute myeloid leukemia synergizes with allo-immune effects to induce sustained responses. Leukemia 26: 2353-2359, 2012.

34. Mathew NR, Baumgartner F, Braun L, O'Sullivan D, Thomas S, Waterhouse M, Müller TA, Hanke K, Taromi S, Apostolova $\mathrm{P}$, et al: Sorafenib promotes graft-versus-leukemia activity in mice and humans through IL-15 production in FLT3-ITD-mutant leukemia cells. Nat Med 24: 282-291, 2018.

35. Darvin P, Toor SM, Sasidharan Nair V and Elkord E: Immune checkpoint inhibitors: Recent progress and potential biomarkers. Exp Mol Med 50: 1-11, 2018.

36. Yao S and Chen L: Adaptive resistance: A tumor strategy to evade immune attack. Eur J Immunol 43: 576-579, 2013.

37. Qin S, Xu L, Yi M, Yu S, Wu K and Luo S: Novel immune checkpoint targets: Moving beyond PD-1 and CTLA-4. Mol Cancer 18: $155,2019$.

38. Jin Z, Lan T, Zhao Y, Du J, Chen J, Lai J, Xu L, Chen S, Zhong X, $\mathrm{Wu}$ X and Li Y: Higher TIGIT ${ }^{+} \mathrm{CD} 226-\gamma \delta$ T cells in patients with acute myeloid leukemia. Immunol Invest: Aug 20, 2020 (Epub ahead of print).

This work is licensed under a Creative Commons Attribution-NonCommercial-NoDerivatives 4.0 International (CC BY-NC-ND 4.0) License. 